\title{
Comparative investigation of the anti-emetic effects of granisetron and palonosetron during the treatment of acute myeloid leukemia
}

\author{
AKI MATSUMARU $^{1}$, YUTAKA TSUTSUMI ${ }^{2}$ and SHINICHI ITO ${ }^{2}$ \\ Departments of ${ }^{1}$ Outpatient Chemotherapy Center and ${ }^{2}$ Hematology, \\ Hakodate Municipal Hospital, Hakodate, Hokkaido 041-0821, Japan
}

Received June 3, 2016; Accepted July 22, 2017

DOI: $10.3892 / \mathrm{mco} .2017 .1350$

\begin{abstract}
Chemotherapy-induced nausea and vomiting has a considerable negative impact on the quality of life of patients with cancer. Unfortunately, there has been little progress in the development of supportive therapies for the anti-emetic treatment of patients with hematopoietic tumors. This lack of supportive treatments motivated the present retrospective comparison between two groups of anti-emetic drugs. The current study aimed to compare granisetron and palonosetron in order to determine which is more effective, based on cases of patients undergoing remission induction therapy and consolidation therapy for the treatment of acute myeloid leukemia. Granisetron or palonosetron were administered in Japanese-approved dosages ( $3 \mathrm{mg}$ granisetron once per day for 5 or 7 days, or one administration of $0.75 \mathrm{mg}$ palonosetron). Patients were randomly selected, and their clinical information was acquired from medical records. The data represent the doctors' and nurses' records. The results demonstrated that palonosetron treatment (in which the drug was administered alone or in combination with aprepitant) was more effective than granisetron treatment for the complete control of acute vomiting. Therefore, in the treatment of hematopoietic malignancies, palonosetron is an effective regimen to be administered alongside more than 5 continuous days of anticancer agents. Furthermore, the combination of palonosetron and aprepitant was found to be the optimal combination. In conclusion, palonosetron is superior to granisetron for the prevention of nausea and vomiting induced by chemotherapy for hematological cancers. In Japan, the standard dose of palonosetron is $0.75 \mathrm{mg}$; a dose of $0.25 \mathrm{mg}$ of palonosetron must be compared with $0.75 \mathrm{mg}$ in future studies.
\end{abstract}

Correspondence to: Miss Aki Matsumaru, Department of Outpatient Chemotherapy Center, Hakodate Municipal Hospital, 1-10-1 Minato, Hakodate, Hokkaido 041-0821, Japan

E-mail: a-matumaru@hospital.hakodate.hokkaido.jp

Key words: granisetron, palonosetron, leukemia, chemotherapy-induced nausea and vomiting

\section{Introduction}

Chemotherapy-induced nausea and vomiting (CINV) causes patients considerable emotional and physical distress, greatly diminishing quality of life (1). Japan has developed clinical practice guidelines that support and aid the implementation of evidence-based practices (2), covering usage of aprepitant, a selective neurokinin 1 receptor antagonist, as well as firstgeneration granisetron and second-generation palonosetron [5-hydroxytryptamine type 3 (5-HT3) receptor antagonists]. Previous studies have made significant progress in the development of supportive therapies for patients receiving cisplatin and doxorubicin + cyclophosphamide; this includes anti-emetic drugs for highly emetogenic chemotherapy (HEC) regimens $(3,4)$. Anti-emetic treatment recommendations for patients receiving $\operatorname{HEC}(5,6)$ and moderately emetogenic chemotherapy (7-9) for the treatment of solid tumors are now well established, and evidence suggests that palonosetron is fairly effective (10).

CINV comprises two of the most unpleasant chemotherapyassociated side effects for patients with cancer, and numerous studies (3-9) have been conducted since 2012 to assess the effectiveness of a growing list of anticancer drug options that are able to reduce CINV. However, balanced against the effectiveness of the treatment as a supportive drug, the cost burden remains a major concern.

Findings from the TRIPLE TEST clinical trial (11), published in 2013 revealed that palonosetron markedly improved the complete recovery (CR) rate during the delayed phase compared with other drug options. The TRIPLE TEST was originally used to assess the advanced emetic risk of cisplatin regimens, but acute and delayed phases overlap in remission induction therapy and other daily continuous administration regimens. This study demonstrated that palonosetron was remarkably effective for controlling acute vomiting.

Patients with hematological tumors (as opposed to solid tumors) are generally younger and have greater risk of CINV due to highly emetogenic treatments and other psychological factors. Unfortunately, there are currently no collective international guidelines for combating CINV in these patients.

The current study is a retrospective comparative analysis of the anti-emetic effects of granisetron and palonosetron when used during remission induction therapy and consolidation therapy of patients with acute myeloid leukemia. 


\section{Patients and methods}

Study participants. The present study included a total of 83 patients diagnosed with acute myeloid leukemia treated between August 2011 and June 2013 with remission induction therapy and consolidation therapy, with a 5-day or 7-day course of cytarabine $\left(100-200 \mathrm{mg} / \mathrm{m}^{2}\right)$ and a three-day course of anthracycline (idarubicin, $12 \mathrm{mg} / \mathrm{m}^{2}$; daunorubicin, $50 \mathrm{mg} / \mathrm{m}^{2}$; aclarubicin, $20 \mathrm{mg} / \mathrm{m}^{2}$; mitoxantrone, $7 \mathrm{mg} / \mathrm{m}^{2}$ ). These patients were selected by the Department of Hematology and Outpatient Chemotherapy Center, Hakodate Municipal Hospital, Hokkaido, Japan.

The study protocol was approved by the Hakodate Municipal Hospital Institutional Review Board (Hakodate, Japan). Based on the Declaration of Helsinki, written informed consent was obtained from all participating patients.

Study methodology. Granisetron or palonosetron were administered at the judgment of the physician in Japanese-approved dosages (3 $\mathrm{mg}$ granisetron once per day for 5 or 7 days, or one dose of $0.75 \mathrm{mg}$ palonosetron). An analysis was performed the rates of complete control (CC) during acute-phase and delayed-phase vomiting of patients receiving the two drugs. The effects of each drug were evaluated as $\mathrm{CC}$, if the following conditions were met: i) No vomiting or dry vomiting; ii) no other anti-emetic treatments; and iii) no moderate or severe nausea. The data were obtained from the doctors' and nurses' records. The daily dosage of aprepitant was as follows: Day 1, $125 \mathrm{mg}$; days 2 and 3, $80 \mathrm{mg}$. Aprepitant is approved in Japan for the use during the early stages of chemotherapy.

Statistical analysis. Fisher's exact test was used to analyze the data and statistical analysis was performed with StatMate series version 5 software (ATMS Co., Ltd., Tokyo, Japan). $\mathrm{P}<0.05$ was considered to indicate a statistically significant difference.

\section{Results}

Age and gender of patients. Patients in the granisetron group ranged in age from 30-80 years, with a median age of 65 years. The palonosetron group ranged in age from 40-80 years, with a median age of 62 years. The granisetron group consisted of 13 female $(29 \%)$ and 32 male $(71 \%)$ patients, whereas the palonosetron group consisted of 17 female $(45 \%)$ and 21 male $(55 \%)$ patients (Table I). There were no significant differences in the patients' age and gender.

Treatments. A detailed breakdown of the treatments analyzed is presented in Table II. The study included 23 cases of granisetron treatment alone, 22 cases of granisetron combined with aprepitant, 23 cases of palonosetron alone and 15 cases of palonosetron treatment combined with aprepitant.

$\mathrm{CC}$ of acute vomiting was achieved in $39 \%$ of the granisetron alone group, $41 \%$ of the combined granisetron + aprepitant group, $70 \%$ of the palonosetron alone group and $80 \%$ of the combined palonosetron + aprepitant group. Significant differences were observed between the palonosetron alone and granisetron alone groups $(\mathrm{P}=0.0458)$ and the combined granisetron + aprepitant and palonosetron + aprepitant groups
Table I. Patient characteristics.

\begin{tabular}{lcc}
\hline & \multicolumn{2}{c}{ Anti-emetic received } \\
\cline { 2 - 3 } Characteristic & Granisetron & Palonosetron \\
\hline Median age, years & 65 & 62 \\
Minimum age, years & 30 & 40 \\
Maximum age, years & 80 & 80 \\
Gender, n (\%) & & $17(45)$ \\
Female & $13(29)$ & $21(55)$ \\
Male & $32(71)$ & \\
\hline
\end{tabular}

Table II. Patient treatment groups.

\begin{tabular}{lcc}
\hline & Granisetron, $\mathrm{n}$ & Palonosetron, $\mathrm{n}$ \\
\hline Total no. of cases & 45 & 38 \\
IDA-AraC & 14 & 13 \\
ACR-AraC & 6 & 4 \\
DNR-AraC & 7 & 9 \\
MIT AraC & 10 & 6 \\
MEC & 8 & 6
\end{tabular}

IDA-AraC, idarubicin + cytarabine; ACR-AraC, aclarubicin + cytarabine; DNR-AraC, daunomycin + cytarabine; MIT-AraC, mitoxantrone + cytarabine; MEC, mitxantrone + etoposide + cytarabine.

Table III. Costs of anti-emetics in dollars.

\begin{tabular}{lccc}
\hline & \multicolumn{3}{c}{ Treatment duration } \\
\cline { 2 - 4 } Anti-emetic & 1 day & 5 days & 7 days \\
\hline Granisetron & 23.36 & 116.8 & 163.5 \\
Palonosetron & 118.0 & 118.0 & 118.0 \\
\hline
\end{tabular}

$(\mathrm{P}=0.0409)$; palonosetron was demonstrated to be the more effective treatment for the $\mathrm{CC}$ of vomiting (Fig. 1).

$\mathrm{CC}$ of delayed vomiting was achieved in $57 \%$ of the granisetron alone group, $41 \%$ of the combined granisetron + aprepitant group, $83 \%$ of the palonosetron alone group and $80 \%$ of the combined palonosetron + aprepitant group. No significant differences were observed between the granisetron alone and palonosetron alone groups $(\mathrm{P}=0.0653)$; however, a somewhat improved performance was observed for the palonosetron group. Comparing the combined granisetron + aprepitant and palonosetron + aprepitant groups yielded a significant difference $(\mathrm{P}=0.0409)$, thus, the combined palonosetron + aprepitant group was effective for the $\mathrm{CC}$ of delayed vomiting (Fig. 2).

In monetary terms, granisetron costs $\$ 23.36$ per $3 \mathrm{mg}$, whereas palonosetron costs $\$ 118.00$ for $0.75 \mathrm{mg}$ of the drug. Using the 5-HT3 receptor antagonists for a regimen lasting several days, granisetron would cost $\$ 116.80$ if taken once per day for 5 days, $\$ 163.50$ if taken once per day for 7 days, 


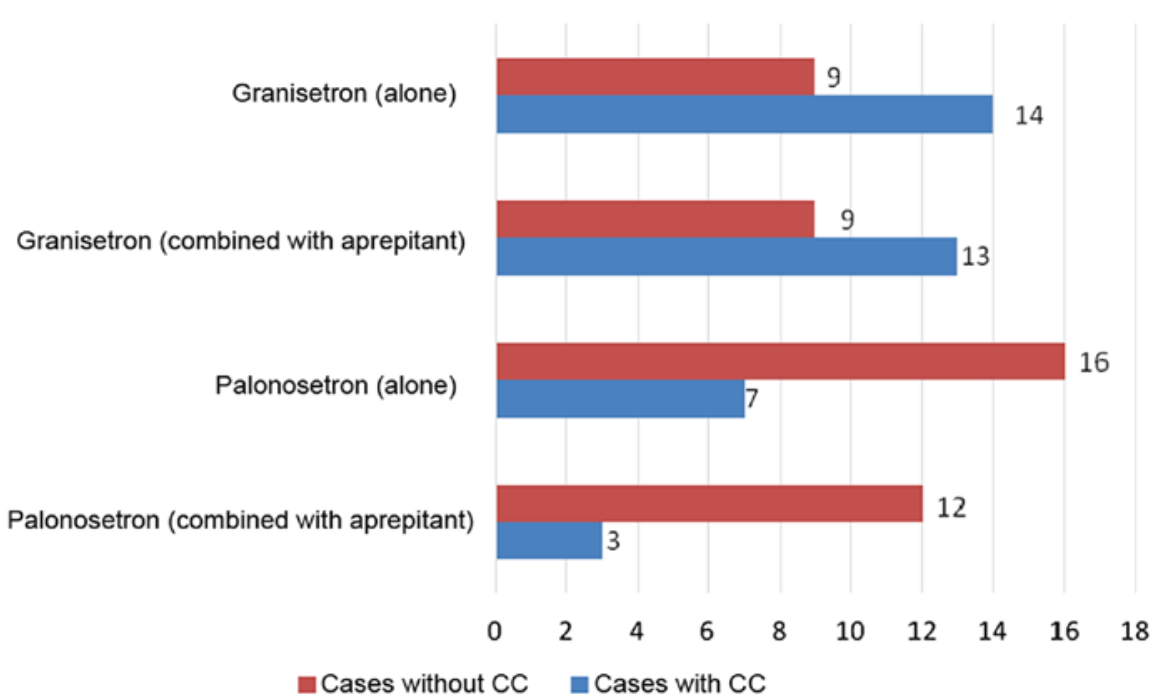

Figure 1. Complete control of acute nausea and vomiting. The palonosetron group was demonstrated to have improved CC. CC, complete control.

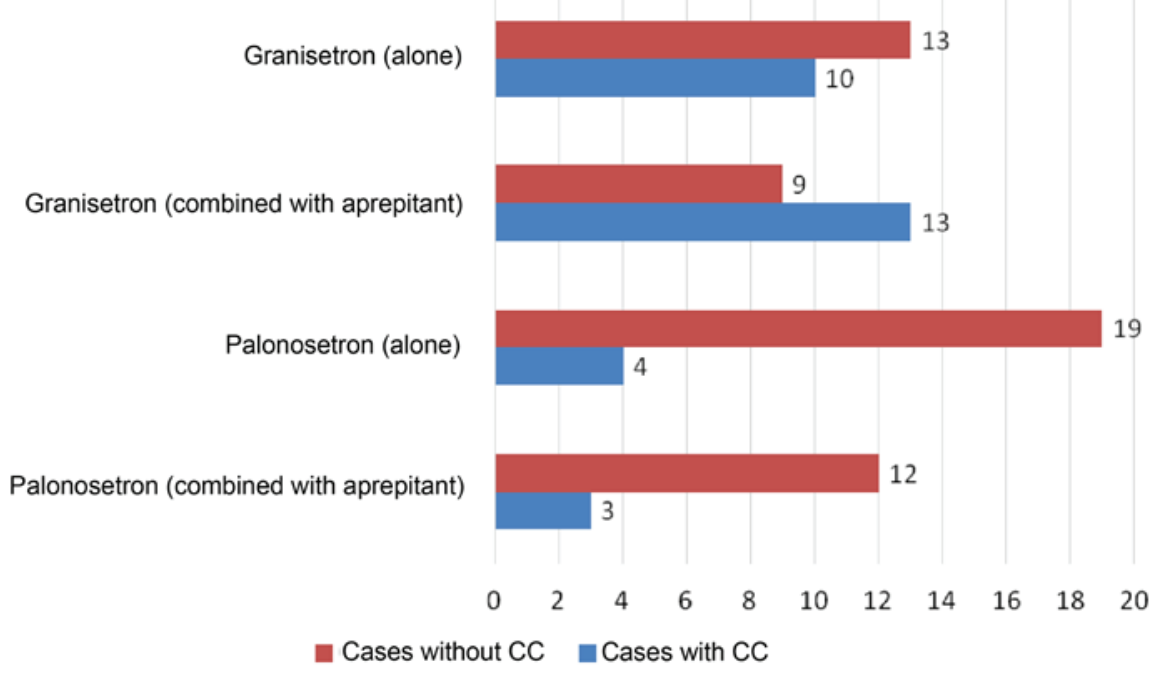

Figure 2: Complete control of delayed nausea and vomiting. In a comparison of single agents, improved performance was observed for the palonosetron group. The combined palonosetron + aprepitant treatment was significantly effective for CC.

$\$ 233.60$ if taken twice per day for 5 days and $\$ 327.10$ if taken twice per day for 7 days. By contrast, palonosetron is administered once per week; therefore, whether or not palonosetron is prescribed for a single day or as a multi-day treatment, the cost remains the same at $\$ 118.00$. Thus, if a 5-HT3 receptor antagonist is administered for longer than 5 days, palonosetron is less expensive than granisetron (Table III).

\section{Discussion}

The efficacy of palonosetron may be attributed to its long plasma elimination half-life and high receptor binding affinity (12) compared with other 5-HT3 receptor antagonists. The superior anti-emetic efficacy of palonosetron compared with other 5-HT3 receptor antagonists may also be attributed to allosteric interactions and a positive cooperative effect of palonosetron, prolonged structural changes of the receptor and internalization (13-15), in addition to other factors.
Several investigators reported that palonosetron provides more effective CINV control through the entire chemotherapy process (including the delayed phase) than any other 5-HT3 receptor to date $(16,17)$. The present results similarly observed that palonosetron is effective for controlling acute- and delayed-phase nausea through the entire treatment period.

Compared with the short half-life of granisetron, $3.14 \pm 1.20 \mathrm{~h}(17)$, palonosetron is eliminated from the body very slowly and has a markedly longer half-life of $41.6 \pm 13.1 \mathrm{~h}$ (18). Hothersall et al (19) reported that palonosetron acts as a 5-HT3 receptor over a prolonged period or even as an irreversible antagonist for at least 4 days. Allosteric receptor-receptor interactions may play a significant role in this phenomenon (19). The key objective of the present study was to identify a continuous daily regimen of anti-emetic drugs that may be used during remission induction therapy. The results revealed that the anti-emetic effects of granisetron last only a relatively short time when the drug is administered once or even twice 
per day; however, the effects of palonosetron persist over its long plasma elimination half-life, which facilitates continuous supportive therapy of a daily regimen following nausea. Furthermore, comparing the relative costs in the treatment of bone and soft tissue tumors, Kimura et al (20) demonstrated that a single dose of palonosetron was in no way inferior to continuous administration of multiple doses of granisetron. In the current analysis, palonosetron is also more cost-effective and is not inferior to granisetron when used in continuous administration regimens.

These results suggest that palonosetron is a highly effective 5-HT3 receptor antagonist anti-emetic for use with the daily administration of an antineoplastic agent, in terms of medical efficacy and cost-effectiveness.

It must be noted that, due to the retrospective study design, the current results may be skewed by the fact that the attending physicians decided whether granisetron or palonosetron were administered alone or in combination with aprepitant. This is an issue that may be addressed in a future study.

Guidelines developed by the Japanese Society of Medical Oncology note that 'When a clinician underestimates the occurrence of nausea, this indicates that vomiting is even less well controlled' (21). Therefore, there is a requirement for further investigation of additional effective anti-emetic therapies in the future.

In conclusion, the results of the present study suggest that, in the treatment of hematopoietic malignancies, palonosetron is an effective regimen to be administered alongside more than 5 continuous days of anti-cancer agents. Furthermore, the combination of palonosetron and aprepitant was revealed to be the optimal regimen.

\section{References}

1. Cohen L, de Moor CA, Eisenberg P, Ming EE and Hu H Chemotherapy-induced nausea and vomiting: Incidence and impact on patient quality of life at community oncology settings. Support Care Cancer 15: 497-503, 2007.

2. Hori K, Kobayashi N, Atsumi H, Nagayama A, Kondoh M, Noge I, Kimura M, Utsugi H, Iwasaki T, Nakamura M, et al Changes in compliance with Japanese antiemetic guideline for chemotherapy-induced nausea and vomiting: A nationwide survey using a distributed research network. Support Care Cancer 22: 969-977, 2014.

3. Rojia F, Herrstedt J, Aapro M, Gralla RJ, Einhorn LH, Ballatori E, et al: Guideline update for MASCC and ESMO in the prevention of chemotherapy-and radiotherapy-induced nausea and vomiting:results of the Perugia consensus conference. Ann Oncol 21 (Suppl 5): 232-243, 2010.

4. Kris MG, Hesketh PJ, Somerfield MR, Feyer P, Clark-Snow R, Koeller JM, Morrow GR, Chinnery LW, Chesney MJ, Gralla RJ, et al; American Society of Clinical Oncology: American Society of Clinical Oncology guideline for antiemetics in oncology: Update 2006. J Clin Oncol 24: 2932-2947, 2006.

5. Aapro MS, Grunberg SM, Manikhas GM, Olivares G, Suarez T, Tjulandin SA, Bertoli LF, Yunus F, Morrica B, Lordick F, et al: A phase III, double-blind, randomized trial of palonosetron compared with ondansetron in preventing chemotherapy-induced nausea and vomiting following highly emetogenic chemotherapy. Ann Oncol 17: 1441-1449, 2006.

6. Kris MG, Tonato M, Bria E, Ballatori E, Espersen B, Herrstedt J, Rittenberg C, Einhorn LH, Grunberg S, Saito M, et al: Consensus recommendations for the prevention of vomiting and nausea following high-emetic-risk chemotherapy. Support Care Cancer 19: S25-S32, 2011.
7. Botrel TEA, Clark OAC, Clark L, Paladini L, Faleiros E and Pegoretti B: Efficacy of palonosetron (PAL) compared to other serotonin inhibitors (5-HT3R) in preventing chemotherapyinduced nausea and vomiting (CINV) in patients receiving moderately or highly emetogenic (MoHE) treatment: Systematic review and meta-analysis. Support Care Cancer 19: 823-832, 2011.

8. Eisenberg P, Figueroa-Vadillo J, Zamora R, Charu V et al: Improved prevention of moderately emetogenic chemotherapy-induced nausea and vomiting with Plonosetron, a pharmacollogically novel 5-HT3 receptor antagonist. Cancer 1: 2473-2482, 2003.

9. Yang LPH and Scott LJ: Palonosetron: In the prevention of nausea and vomiting. Drugs 69: 2257-2278, 2009.

10. Rojas C, Stathis M, Thomas AG, Massuda EB, Alt J, Zhang J, Rubenstein E, Sebastiani S, Cantoreggi S, Snyder SH, et al: Palonosetron exhibits unique molecular interactions with the 5-HT3 receptor. Anesth Analg 107: 469-478, 2008.

11. Suzuki K, Yamanaka T, Hashimoto H, Shimada Y, Arata K, Matsui R, Goto K, Takiguchi T, Ohyanagi F, Kogure Y, et al: Randomized, double-blind, phase III trial of palonosetron versus granisetron in the triplet regimen for preventing chemotherapy-induced nausea and vomiting after highly emetogenic chemotherapy: TRIPLE study. Ann Oncol 27: 1601-1606, 2016.

12. Navari RM: Pharmacological management of chemotherapyinduced nausea and vomiting: Focus on recent developments. Drugs 69: 515-533, 2009.

13. Rojas C, Thomas AG, Alt J, Stathis M, Zhang J, Rubenstein EB, Sebastiani S, Cantoreggi S and Slusher BS: Palonosetron triggers 5-HT(3) receptor internalization and causes prolonged inhibition of receptor function. Eur J Pharmacol 626: 193-199, 2010.

14. Saito $M$ and Tsukuda M: Review of palonosetron: Emerging data distinguishing it as a novel 5-HT(3) receptor antagonist for chemotherapy-induced nausea and vomiting. Expert Opin Pharmacother 11: 1003-1014, 2010.

15. Saito M, Aogi K, Sekine I, Yoshizawa H, Yanagita Y, Sakai H, Inoue K, Kitagawa C, Ogura T and Mitsuhashi S: Palonosetron plus dexamethasone versus granisetron plus dexamethasone for prevention of nausea and vomiting during chemotherapy: A double-blind, double-dummy, randomised, comparative phase III trial. Lancet Oncol 10: 115-124, 2009.

16. Schwartzberg L, Barbour SY, Morrow GR, Ballinari G, Thorn MD and Cox D: Pooled analysis of phase III clinical studies of palonosetron versus ondansetron, dolasetron, and granisetron in the prevention of chemotherapy-induced nausea and vomiting (CINV). Support Care Cancer 22: 469-477, 2014.

17. Phase I clinical trial of granisetron(part2)-Pharmacokinetics at the time of single and repeated intravenous administration. Rinsho Iyaku Jpn 6 (suppl-5): 25-34, 1990.

18. Maemoto $M$ and Tsukuda M, et al: A PhaseIIstudy of palonosetron combined with dexamethasone to prevent nausea and vomiting induced by highly emetogenic chemotherapy. Ann Oncol 20: 1874-1880, 2009.

19. Hothersall JD, Moffat C and Connolly CN: Prolonged inhibition of 5-HT receptors by palonosetron results from surface receptor inhibition rather than inducing receptor internalization. Br J Pharmacol 169: 1252-1262, 2013.

20. Kimura H, Yamamoto N, Shirai T, Nishida H, Hayashi K, Tanzawa Y, Takeuchi A, Igarashi K, Inatani H, Shimozaki S, et al: Efficacy of triplet regimen antiemetic therapy for chemotherapyinduced nausea and vomiting (CINV) in bone and soft tissue sarcoma patients receiving highly emetogenic chemotherapy, and an efficacy comparison of single-shot palonosetron and consecutive-day granisetron for CINV in a randomized, singleblinded crossover study. Cancer Med 4: 333-341, 2015.

21. Basch E, Prestrud AA, Hesketh PJ, Kris MG, Feyer PC, Somerfield MR, Chesney M, Clark-Snow RA, Flaherty AM, Freundlich B, et al; American Society of Clinical Oncology: Antiemetics: American Society of Clinical Oncology clinical practice guideline update. J Clin Oncol 29: 4189-4198, 2011. 